Table of contents entry:

Higher Alcohol Synthesis: Product Analysis using the Concept of Effective Carbon Numbers

B. Frank, Z.-L. Xie, A. Trunschke*

The selectivity of Fischer Tropsch synthesis can be tuned to produce high fractions of oxygenates, depending on catalyst and reaction conditions. The concept of effective carbon numbers turns out to be a useful tool for facile and rapid GC/MS calibration to avoid the abundance of chemicals required for sound quantification. 


\title{
Higher Alcohol Synthesis: Product Analysis using the Concept of Effective Carbon Numbers
}

Benjamin Frank, Zai-Lai Xie, Annette Trunschke*

Department of Inorganic Chemistry, Fritz Haber Institute of the Max Planck Society, Faradayweg 4-6, D-14195 Berlin, Germany

*) Corresponding author: Dr. Annette Trunschke; Fax: +49 308413 4401; Email: trunschke@fhi-berlin.mpg.de

\begin{abstract}
A catalytic set-up for Fischer-Tropsch synthesis to alkanes and alcohols is described. Within this single-channel reactor unit the reaction conditions can be varied in the ranges of 25$400^{\circ} \mathrm{C}, 1-100 \mathrm{bar}$, and $300-120,000 \mathrm{~h}^{-1}$ (GHSV). The broad product spectrum is efficiently analyzed by GC/MS. The concept of effective carbon numbers, as typically applied in refining and high-molecular chemistry, is suitable for the product spectrum comprising mainly alkanes, alkenes, alcohols, aldehydes, and carboxylic acids. This article provides details about the setup and general measurement procedures.
\end{abstract}

\section{Keywords}

Fischer Tropsch synthesis, higher alcohol synthesis, product analysis, effective carbon numbers, gas chromatography 


\section{Introduction}

Fischer-Tropsch synthesis (FTS) regains interest as an important strategy for providing a broad organochemical feedstock to overcome consequences for chemical industry associated with the depletion of crude oil resources. The product spectrum depends on reaction conditions and active components as well as promoters and structural properties of the catalyst. Syngas supplied from coal or biomass gasification can be readily converted into alkanes, alkenes, aromatics, and various oxygenates such as alcohols, aldehydes, or carboxylic acids. To account for this potential future key process in energy-related chemistry a suitable catalytic set-up for its investigation has recently been installed at Fritz Haber Institute, Berlin. The research project is embedded in the Inno.CNT innovation alliance ${ }^{[1]}$ to explore potential applications of multi-walled carbon nanotubes (CNTs) as an efficient catalyst support. For some heterogeneously catalyzed reactions CNTs show superior support properties over conventional carbons, which is particularly true for FTS. One possible concept to explain this observation is the confinement effect. ${ }^{[2]}$

Table 1 lists typical reaction conditions applied for the investigation of higher alcohol synthesis (HAS) in a fixed bed reactor. It is seen that reaction conditions required for oxygenate formation can be much harsher than in the common paraffin-targeting FTS, which typically operates below $5 \mathrm{MPa}$. Thus, aspects such as hydrogen embrittlement and metal dusting associated with the exposition of the reactor steel to $\mathrm{H}_{2}$ and carbon containing atmospheres at elevated temperatures must be considered for long-term high pressure stability ${ }^{[3,4]}$.

Table 1. Typical reaction conditions of HAS over different catalysts.

\begin{tabular}{|c|c|c|c|c|c|c|}
\hline Catalyst & $\begin{array}{ll}\mathrm{T} & I \\
{ }^{\circ} \mathrm{C} & \end{array}$ & $\begin{array}{ll}p & l \\
\mathrm{MPa}\end{array}$ & $\mathrm{H}_{2} / \mathrm{CO}$ & $\begin{array}{l}\text { GHSV I } \\
\mathbf{h}^{-1}\end{array}$ & $\begin{array}{l}X(\mathrm{CO}) \quad I \\
\%\end{array}$ & Ref. \\
\hline $\mathrm{Ni} / \mathrm{MoS}_{2}$ & 340 & 9.5 & 1.0 & 8,500 & 27 & [5] \\
\hline $\mathrm{K} / \mathrm{Ni} / \mathrm{Mo}_{2} \mathrm{C}$ & 300 & 8.0 & 1.0 & 2,000 & 73 & {$[5]$} \\
\hline $\mathrm{Rh} / \mathrm{Mn} / \mathrm{SiO}_{2}$ & 300 & 5.5 & 2.0 & 3,750 & 41 & [6] \\
\hline $\mathrm{Cs} / \mathrm{Cu} / \mathrm{ZnO}$ & 310 & 7.6 & 0.45 & 3,260 & $\sim 20$ & {$[7]$} \\
\hline $\mathrm{ZnO} / \mathrm{Cr}_{2} \mathrm{O}_{3} / \mathrm{K}_{2} \mathrm{O}$ & 405 & 8.5 & 1.0 & 8,000 & - & [8] \\
\hline
\end{tabular}


The superior challenge, however, is the product analysis. Typically some tens of hydrocarbon and oxygenated products are formed is gas and liquid state, which have to be identified and quantified accurately. High-molecular products such as waxes may stick in the gas lines, thus can be difficult to analyze. Moreover the liquid products often separate in aqueous and organic phases, which renders the exact quantification of products even more complicated the smaller the reactor and, consequently, the formation rate of products is. As a consequence, carbon balances near $100 \%$ are rarely found in literature except for autoclave/batch experiments. Unfortunately, detailed procedures of FTS product analysis as well as calibration routines are typically not reported in literature..$^{[2,9,10]}$

To facilitate product analysis by gas chromatography (GC) we make use of the concept of effective carbon numbers (ECN) developed in the early 1960's. ${ }^{[1]}$ This method correlates the structural increments of an organic molecule with the flame ionization detector (FID) response of the GC. Some refinement and extensions have been published later. ${ }^{[12-14]}$ According to Sternberg et al. the ECN is defined as the chain length of an alkane, which has an FID response equal to that of the sample molecule (Eq. 1)..$^{[1]}$

$E C N_{i}=E C N_{s} \frac{A_{i} m_{s} M_{i}}{A_{s} m_{i} M_{s}}$

Here, $A, m$, and $M$ are FID peak area, mass (fraction), and molar mass, respectively, whereas indices $i$ and $s$ stand for the compound under investigation and the reference substance, respectively. To our surprise the combination of ECN and FTS is not reported in literature. Instead, ECN is typically associated with the analysis of fatty acids, biomolecules, surfactants, or pesticides, i.e., larger or more complex molecules. It is also used for molecules that are not available in the pure form, or if preparation is very expensive.

Besides giving a precise description of our reactor set-up we show that this method is suitable for analysis of a typical product gas mixture obtained 


\section{Catalytic set-up for HAS}

The flow diagram of the single-reactor set-up for HAS is presented in Fig. 1. Pre-mixed syngas with an $\mathrm{H}_{2} / \mathrm{CO}$ ratio of 1.0 and $\mathrm{Ar}$ as the internal standard $\left(49.5 \% \mathrm{H}_{2}, 49.5 \% \mathrm{CO}, 1 \%\right.$ $\mathrm{Ar}$ ) as well as pure $\mathrm{H}_{2}$ and $\mathrm{He}$ in $>4.0$ grades are supplied by Westfalen. After passing $2 \mu \mathrm{m}$ filter units the final gas composition is adjusted with mass flow controllers. Helium can be used as reactant or product diluent, respectively (V13). The reactor pressure can be adjusted with an overflow pressure relief valve V18, which is located in a heating box T1 (Heraeus) at $70^{\circ} \mathrm{C}$, in the range of $1-100$ bar. Before entering the catalytic reactor $\mathrm{R} 2$, the reactant gas must pass a carbonyl trap R1, which is a stainless steel cartridge filled with $5 \mathrm{~g}$ activated carbon $^{[15]}$ pellets (Chemviron Carbon AP3-60), to protect the catalyst from metal contamination.

The reactor is made of 1.4435 stainless steel, which is reported to resist pure $\mathrm{H}_{2}$ and $\mathrm{CO}$ at up to $1000^{\circ} \mathrm{C}$ and $870^{\circ} \mathrm{C}$, respectively. ${ }^{[16]}$ Gases in a gas mixture can synergize in the corrosion, however, the structural integrity of the 1/2" tube (length: $40 \mathrm{~cm}$; inner diameter: $0.85 \mathrm{~cm}$ ) has been tested for 2 weeks in $\mathrm{H}_{2} / \mathrm{CO}$ at $400^{\circ} \mathrm{C}$ and 100 bar. Nevertheless, for each experiment a fresh reactor is used to avoid problems with corrosion and possible (catalytically active) metal deposition at the inner reactor wall. The temperature in the reactor is measured with a thermocouple located on top of the catalyst bed. The reactor itself is fixed and heated in a vertical clamshell furnace T2 (HTM Reetz). An aluminium core tightly wraps the reactor to provide an isothermal zone of $10 \mathrm{~cm}$ with a temperature variation of $\pm 1 \mathrm{~K}$ allowing for the testing of up to $5 \mathrm{ml}$ catalyst grains. Typically, a sieve fraction of $200-300 \mu \mathrm{m}$ is chosen to minimize the impact of mass transfer limitation on the catalytic performance while maintaining a sufficiently high permeability of the catalyst bed.

The reaction products are directly piped into a condenser T3 operating at $16^{\circ} \mathrm{C}$. In case of high CO conversion additional He from V13 can be used to flush residual gaseous compounds to GC and mass spectroscopic analysis (GC/MS). Liquid products can be removed for analysis by using the needle valve V16, which enables controlled and complete discharge of the condenser even at an operation pressure of 100 bar. Remaining gaseous compounds re-enter the heating box T1 to pass the 4-way crossover valve V15 and the 
pressure relief valve V18 with minimum risk of condensation. The decompressed product gas is then piped to GC/MS analysis via a heated Teflon ${ }^{\circledR}$ tubing T4 (Hillesheim) operating at $100^{\circ} \mathrm{C}$.

For safety reasons substantial part of the high-pressure unit is located in a closed heating box, which is continuously drawn off by a vent. Pressure relief valves V4, V5, V6, and V14 open automatically as a critical pressure is exceeded, additionally, V14 can be manually opened to decompress the set-up. All MFCs can be operated in slave function with respect to the reaction pressure, i.e., the gas flow would automatically stop in case of heavy leakage.

\section{GC/MS product analysis}

Reaction products are identified and quantified using an Agilent 5975B GC/MS. For the gaseous products, Ar is used as the internal standard. Plot Q $(30 \mathrm{~m} \times 0.53 \mathrm{~mm} \times 40 \mu \mathrm{m})$ and Plot Molsieve $(30 \mathrm{~m} \times 0.53 \mathrm{~mm} \times 50 \mu \mathrm{m})$ columns are installed for the separation of light gases $\left(\mathrm{H}_{2}, \mathrm{Ar}, \mathrm{CO}, \mathrm{CO}_{2}\right)$ using a temperature program in the range of $40-140^{\circ} \mathrm{C}$. Volatile hydrocarbons $\left(<\mathrm{C}_{6}\right)$ and oxygenates $\left(<\mathrm{C}_{3}\right)$ are separated on a DB-1 $(60 \mathrm{~m} \times 0.32 \mathrm{~mm} \times 5$ $\mu \mathrm{m})$ column. Light gases are monitored with a thermal conductivity detector (TCD). Instead, hydrocarbons and oxygenates are analyzed in parallel by MS and flame ionization detectors (FID). Gases were calibrated with appropriate certified gas mixtures using a one point calibration for $\mathrm{C}_{1}-\mathrm{C}_{6}$ alkanes and acetaldehyde (Tab. 2), whereas two points were measured for $\mathrm{H}_{2}, \mathrm{Ar}, \mathrm{CO}$, and $\mathrm{CO}_{2}$.

Liquid products are collected in the condenser T3 (Fig. 1) and taken for analysis after a defined reaction time. Here, aqueous and organic phases are thoroughly separated by extraction of non-polar compounds with toluene, which is also used as an internal standard and reference for ECN calculation. Both phases are consecutively separated on the DB-1 column using a non-linear temperature ramp from 50 to $270^{\circ} \mathrm{C}$. For calibration a series of mixtures was prepared using analytical grade compounds as listed in Tab. 2, which further contains the results of 4-point calibrations. The ECN according to Sternberg et al. ${ }^{[11]}$ (with the 
ester increment of -1.5 according to Kállai et al. ${ }^{[17]}$ ) as well as the experimental deviation from predicted FID sensitivities are also given.

Table 2. Hydrocarbons and oxygenates used for GC/MS calibration.

\begin{tabular}{|c|c|c|}
\hline Compound & ECN & Deviation $^{1}$ \\
\hline methanol & 0.4 & $14.7 \%(\mathrm{I})$ \\
\hline ethanol & 1.4 & $0.3 \%(\mathrm{I})$ \\
\hline 1-propanol & 2.4 & $3.2 \%(I)$ \\
\hline 1-butanol & 3.4 & $2.8 \%(I)$ \\
\hline 1-pentanol & 4.4 & $3.5 \%(I)$ \\
\hline acetaldehyde & 1 & $7.2 \%(\mathrm{~g})$ \\
\hline propionaldehyde & 2 & $16.1 \%(\mathrm{I})$ \\
\hline formic acid ${ }^{2}$ & 0 & - \\
\hline acetic acid & 1 & $5.7 \%(\mathrm{I})$ \\
\hline propionic acid & 2 & $8.8 \%(I)$ \\
\hline ethyl acetate & 2.5 & $27.7 \%(\mathrm{I})$ \\
\hline diethylether & 3 & $8.0 \%(\mathrm{l})$ \\
\hline methane & 1 & $11.9 \%(g)$ \\
\hline propane & 3 & $4.0 \%(\mathrm{~g})$ \\
\hline pentane & 5 & $\begin{array}{l}3.2 \%(g) \\
5.0 \%(\mathrm{l})\end{array}$ \\
\hline hexane & 6 & $\begin{array}{l}1.9 \%(\mathrm{~g}) \\
11.6 \%(\mathrm{l})\end{array}$ \\
\hline octane & 8 & $0.3 \%(I)$ \\
\hline decane & 10 & $0.4 \%(I)$ \\
\hline 1-pentene & 4.9 & $4.2 \%(\mathrm{I})$ \\
\hline 1-hexene & 5.9 & $8.5 \%(I)$ \\
\hline
\end{tabular}


In general the ECN concept predicts the FID response factors very well with deviations $<5 \%$ for alcohols and alkanes. During calibration, a notable non-linearity is observed for propionaldehyde, ethyl acetate, and liquid hexane, which is likely due to trimerization, hydrolysis, and presence of isomers, respectively, as identified by appearance of corresponding by-products in the calibration chromatograms. It is assumed that for this reason the deviation from ECN concept is the highest among the compounds investigated (indicated by arbitrary error bars in Fig. 2). Such side reactions should be kept in mind when analyzing the broad FTS product spectrum, for instance, if the question arises whether ester formation occurs by heterogeneous catalysis during HAS or in the liquid product mixture due to the presence of high concentrations of alcohols and organic acids.

On the other hand, the deviation of small molecules such as methane and methanol, which represent the lower end of respective homologues series, is relatively high indicating a limitation of ECN prediction for these molecules. As a consequence, here, for HAS product analysis the experimental calibration factors are used instead of ECN-based predictions.

The conversion of CO during FTS is calculated using the internal Ar standard (Eq. 2). The formation rates of hydrocarbons and oxygenates are calculated on the basis of ECN (except for methanol and methane). Product selectivities are reported in terms of carbon atoms in the reaction products (Eq. 3). Finally, the definition of the carbon balance is given in Eq. 4 .

$X_{C O}=\frac{c_{C O, \text { in }}-c_{C O, \text { out }}}{c_{C O, \text { in }}} \times \frac{c_{A r, \text { in }}}{c_{A r, \text { out }}}$

$S_{i}=\frac{c_{i} / n_{C, i}}{\sum_{j} c_{j} / n_{C, j}}$

$C_{b a l}=\frac{\dot{n}_{C, \text { out }}}{\dot{n}_{C, \text { in }}}$

An oxygenate-containing product composition as obtained over a supported $\mathrm{Rh}$ catalyst at 100 bar and $350^{\circ} \mathrm{C}$ is shown in Fig. 3. The liquid product collected from the cool trap amounted to $757.7 \mathrm{mg}$ after a reaction time of $3.7 \mathrm{~h}$. The CO conversion within this experiment is at around $18.7 \%$. More than 100 different reaction products could be identified by GC/MS. Reaction products denoted as "others" comprise multiply functionalized molecules 
such as, e.g. acetals, and such compounds, which cannot be identified by MS due to low concentrations $(<0.015 \%)$. For calculation of the carbon balance, the latter are handled as methylene units. The catalyst weight as measured after a reaction period of 5 days remained almost constant, confirming the absence of heavy coke and/or condensate formation.

Detailed analysis of the product spectrum reveals that both major product classes alkanes and (primary) alcohols follow the Schulz-Flory product distribution, respectively (Fig. 3b), which is typically observed in FTS and HAS processes. ${ }^{[18]}$ Only very short chain compounds methane, ethane, and methanol show a major deviation, which is attributed to secondary reactions and/or different reaction mechanisms for these products. However, together with a carbon balance of $101.6 \%$ this indicates that the ECN concept can be applied for HAS product analysis enabling a rapid and facile calibration process of the GC/MS device.

\section{Acknowledgement}

Financial support by the Federal Ministry of Education and Research (BMBF) within the CarboKat project (FKZ 03X0204C) of the Inno.CNT alliance ${ }^{[1]}$ is gratefully acknowledged.

\section{References}

[1] "Inno.CNT - Innovationsallianz Carbon Nanotubes," can be found under http://www.innocnt.de/, 2010.

[2] W. Chen, Z. Fan, X. Pan, X. Bao, J. Am. Chem. Soc. 2008, 130, 9414-9419.

[3] L. Garverick, Corrosion in the Petrochemical Industry, ASM International, 1994.

[4] G. Y. Lai, High-Temperature Corrosion and Materials Applications, ASM International, 2007.

[5] K. Fang, D. Li, M. Lin, M. Xiang, W. Wei, Y. Sun, Catal. Today 2009, 147, 133-138.

[6] J. Hu, Y. Wang, C. Cao, D. C. Elliott, D. J. Stevens, J. F. White, Catal. Today 2007, 120, 90-95.

[7] J. G. Nunan, C. E. Bogdan, K. Klier, K. J. Smith, C.-W. Young, R. G. Herman, J. Catal. $1989,116,195-221$.

[8] E. Tronconi, C. Cristiani, N. Ferlazzo, P. Forzatti, P. L. Villa, I. Pasquon, Appl. Catal. 1987, 32, 285-292.

[9] X.-Y. Quek, Y. Guan, R. A. van Santen, E. J. M. Hensen, ChemCatChem 2011, 3, 17351738. 
[10] J. Kang, S. Zhang, Q. Zhang, Y. Wang, Angew. Chem. Int. Ed. 2009, 48, 2565-2568.

[11] J. C. Sternberg, W. S. Gallaway, D. T. L. Jones, in Gas Chromatography: Third International Symposium Held Under the Auspices of the Analysis Instrumentation Division of the Instrument Society of America (Eds.: N. Brenner, J.E. Callen, M.D. Weiss), Academic Press, 1962, pp. 231-267.

[12] A. D. Jorgensen, K. C. Picel, V. C. Stamoudis, Anal. Chem. 1990, 62, 683-689.

[13] J. T. Scanlon, D. E. Willis, J. Chromatogr. Sci. 1985, 23, 333-340.

[14] M. Kállai, V. Máté, J. Balla, Chromatographia 2003, 57, 639-644.

[15] T. C. Golden, T. H. Hsiung, K. E. Snyder, Ind. Eng. Chem. Res. 1991, 30, 502-507.

[16] K. M. Pruett, Chemical Resistance Guide for Metals \& Alloys, Compass Publications, 1995.

[17] M. Kállai, Z. Veres, J. Balla, Chromatographia 2001, 54, 511-517.

[18] G. Henrici-Olivé, S. Olivé, Angew. Chem. Int. Ed. 1976, 15, 136-141. 


\section{Figure titles}

Figure 1. Flow diagram of the catalytic set-up for HAS. V: valve; F: filter; MFC: mass flow controller; R: reactor; T: temperature controller.

Figure 2. Parity plot of theoretical and experimental FID sensitivity factors for typical HAS reaction products (see Tab. 2).

Figure 3. a) Integral product selectivities (in mol\% of carbon) in an exemplarily FTS product mixture on $\mathrm{a} \mathrm{CO}_{2}$-free basis; b) fraction of linear alkanes and linear primary alcohols. 